\title{
SocArXiv
}

Preprint : March 3, 2022

RedURL/DOI GOES HERE

\section{Is what they aspire what they get? The role of cultural heterogeneity in the classroom for the realization of Abitur aspirations}

\author{
Maria Gerth \\ Universität zu Köln
}

\begin{abstract}
Even though the German education system is characterized by strong between-school tracking, routes to tertiary education are diverse. Students not initially placed in a school track leading straight to the qualification for enrolling in tertiary education, i.e. the Abitur, are able to revise their initial track placement and attain Abitur after all. While students are increasingly taking those non-standard routes to Abitur, evidence suggests that even more aspire than actually attain it. In this paper, I test whether cultural heterogeneity in educational models can account for this. For disadvantaged neighborhoods in the U.S., it has been shown that cultural heterogeneity contributes to decreased realization of college aspirations because adolescents have a harder time to stick to their educational goals. To test whether this explanation is equally applicable to the aspiration realization of German students, this paper uses longitudinal data of CILS4EU. Linear probability models are estimated to test whether cultural heterogeneity in class contributes to the non-realization of aspirations for students on non-standard routes to Abitur. I do not find strong support for this hypothesis. Several robustness checks do not yield a substantially different picture.
\end{abstract}

Keywords: cultural heterogeneity, peer effects, educational aspirations, academic achievement.

\section{Introduction}

Germany is often viewed as a prime example of a highly stratified education system (Buchmann and Park 2009), characterized by early between-school tracking and a clear hierarchy between the different types of secondary schools. Notwithstanding, educational reforms from the 1960s onward have introduced alternative pathways that allow for the revision of initial track placement and offer students a 'second chance' to attain the qualification for enrolling in tertiary education, i.e. the Abitur (Schindler 2017). Those reforms were successful in 
that they were ensued by an increase of students taking non-standard routes to attain Abitur (Buchholz and Schier 2015; Schindler 2017; Biewen and Tapalaga 2017). However, there has been an increasing misalignment of adolescents' educational aspirations and the degrees they attain (Schoon 2010; Jacob and Wilder 2010; Domina, Conley, and Farkas 2011; Reynolds and Johnson 2011; Schneider and Stevenson 1999), suggesting that even more students aspire Abitur than attaining it.

So why do some students on a non-standard route to Abitur end up realizing their aspirations while others do not? One possible explanation that has recently been put forward centers around cultural heterogeneity in educational models students are exposed to (Harding 2011, 2007). It suggests that being surrounded by a wide array of competing and conflicting cultural models of education, hampers constructing and following coherent educational pathways that successfully lead to the realization of adolescents' educational goals. ${ }^{1}$ While this explanation has been successfully applied for cultural heterogeneity on the neighborhood level in the U.S. (Berg, Stewart, Stewart, and Simons 2013; Harding 2011), it is an open question whether adolescents face similar struggles in translating their educational aspirations when they are exposed to a heterogeneous environment in school. Although neighborhood and school context are correlated, research finds that they independently influence adolescents' outcomes (Kirk 2009). Moreover, it is unclear whether results based on US-American samples (Merolla 2016; Berg et al. 2013; Harding 2010, 2011) are applicable to other educational contexts, such as Germany. Especially within the highly stratified German education system, where track placement is early and routes to Abitur are diverse, students might be vulnerable to cultural heterogeneity. Therefore, this study asks whether cultural heterogeneity in class hampers the realization of Abitur-aspirations for students on non-standard educational pathways.

Using panel data of the German CILS4EU study (Kalter, Kogan, and Dollmann 2021; Kalter, Heath, Hewstone, Jonsson, Kalmijn, Kogan, and Tubergen 2017, 2015; Kalter, Heath, Hewstone, Jonsson, Kalmijn, Kogan, Tubergen, Kroneberg, Rydell, Låftman, Dollmann, Engzell, Geven, Horr, Huuva, Jacob, Jaspers, Kruse, Meenakshi, Rudolphi, Salikutluk, Smith, and Zantvliet 2014), this study does not find strong evidence for an influence of cultural heterogeneity on the realization of adolescents' Abitur aspirations in Germany. To gain a better understanding of these results, several post-hoc analyses are conducted.

\section{The role of cultural heterogeneity in educational goal attainment}

In the study of neighborhood disadvantage, Harding (2010) introduced the concept of cultural heterogeneity as an explanation for lower educational outcomes of adolescents in those neighborhoods. He proposed that disadvantaged neighborhoods are cultural heterogeneous environments, in which a variety of cultural models regarding education are present, i.e. receive social support. Those cultural models are conceptualized as frames and scripts (Harding 2010: 141-148) that help people interpret and react to events (frames) and provide templates for sequences of behavior to solve problems or achieve goals (scripts). In disadvantaged neighborhoods, a wide array of those, often contradicting and inconsistent, educational models exists and adolescents acquire them through social interaction or direct observation of others in

\footnotetext{
${ }^{1}$ Along similar lines, Buchmann (1989) argued that homogeneous social groups give their members a clear sense regarding opportunities and boundaries of given roles and positions. Social groups who are more diverse in their lifestyles, action orientations and values on the other hand are not able to provide the same clear picture, resulting in a looser coupling of educational expectations and attainment.
} 
their social context. But this variety of frames and scripts exacerbates their decision-making process and results in delayed action or decision-making (Harding 2010: 158). Because fewer person have taken a specific educational path, each path is less clearly defined, there will be on average less information about how to carry through with it, and less examples of how to follow a particular script exist (Harding 2010: 157). Because social support exists for different models, the social environment will send a weaker signal about which option is the best one. When there is less consensus or agreement for a certain option, adolescents will have a harder time deciding. With a wider array of cultural models comes a weaker commitment to a chosen educational option because there are always other options available, approved and successfully adopted by the social environment (Harding 2010: 156). And especially during adolescence, willingness to 'try on' various cultural models is high (Harding 2010: 160). Therefore, adolescents struggle with developing coherent and clear strategies to achieve their goals. It is easy to switch to different educational pathways when problems arise, lowering adolescents' commitment to the educational path they once chose. While this might be beneficial in the short-term (e.g. through resolving current frustration with failing), it might be detrimental in the long run, by making it less likely to follow through with the more ambitious educational goal.

This argumentation can be applied to the research question of this paper. For cultural heterogeneity to matter, the cultural models need to be contradictory and lead to different pathways (Harding 2010: 160). Those conditions are met in the school context in Germany as well. Choosing lower or intermediate secondary tracks will enable students to take on vocational training but only degrees from upper secondary tracks give them access to higher education. Especially adolescents should be affected by cultural heterogeneity among their peers because they try to establish themselves independent of their parents and rely on their friends as role models and are willing to accept their advice (Hallinan and Williams 1990). Given the importance of classroom composition for shaping adolescents' educational outcomes (Rodkin and Ryan 2012; Burke and Sass 2013), I expect that cultural heterogeneity in the classroom as well hampers adolescents' aspiration realization in Germany.

So when educational aspirations in class are heterogeneous, social support should be weaker for Abitur compared to classrooms with homogeneous Abitur aspirations. Moreover, information regarding the pathway to attain an Abitur is more limited when classmates aspire different degrees. At the same time, degrees other than Abitur are a viable alternative when difficulties are faced on the road to Abitur. It follows that in classrooms with high aspiration heterogeneity, adolescents will have difficulties to follow through with their Abitur aspirations, making it less likely for them to translate their aspirations into an educational degree. Classrooms in which the educational goals of the members are more aligned, will not provide as many distracting alternatives to the ones adolescents originally chose. Therefore, it will be easier for them to follow their plan to attain Abitur, making it more likely for those students to realize their educational aspirations. Therefore, I hypothesize that in classrooms, where educational aspirations are diverse, adolescents will be less likely to realize their Abitur aspirations compared to classrooms with a greater homogeneity in educational aspirations.

\section{Literature Review}

When it comes to peers in school, a large body of research supports the importance of classroom composition for adolescents' achievement (e.g. Hanushek, Kain, Markman, and Rivkin 
2003; Marotta 2017; Burke and Sass 2013; Rodkin and Ryan 2012) and their choice of educational pathways (e.g. Riegle-Crumb, Farkas, and Muller 2006; Hanson 1994; Fletcher 2012). There is even a longstanding debate about the advantages and drawbacks of homogeneous versus heterogeneous classroom environments (see Scharenberg 2012). However, this research usually centers around ability grouping and finds different effects, depending among other things on subject (e.g. Lehmann 2006), grade (e.g. Scharenberg 2012) or own achievement (e.g. Burke and Sass 2013; Marotta 2017), with some studies finding no effect at all (e.g. Hanushek et al. 2003; Kiss 2013). To the authors' knowledge, no study exists that specifically examined heterogeneous educational goals in school as influencing factor of aspiration realization.

But the influence of cultural heterogeneity is supported when it comes to the neighborhood environment. Conducting unstructured, in-depth interviews with sixty black and Latino adolescent boys in 2003/2004, Harding (2010) contrasted the experience of adolescents from poor neighborhoods in Boston with those from lower middle-class neighborhoods. He found that in disadvantaged neighborhoods, models for alternative pathways to college (like dropping out of high school, taking the GED and go to community college) as well as alternatives to college (e.g. the star career) were present and received social support. This led boys to develop strategies to college that were inconsistent, shift educational models when they encountered problems or take riskier educational pathways due to misinformation. Building on those qualitative findings, Harding (2011) used longitudinal data from AddHealth to find that cultural heterogeneity was associated with a lower likelihood of realizing one's college goals in a large and representative sample of US-adolescents as well. Those living in more cultural heterogeneous neighborhoods (operationalized as neighborhoods in which other adolescents are less likely to implement their plans to go to college), were less likely to attend college. Using a similar analytical strategy, this finding was replicated for a sample of roughly 700 Black adolescents in Iowa and Georgia (Berg et al. 2013). When using self-efficacy, i.e. an individual's belief about their ability to shape their own lives, to measure cultural heterogeneity, NELS data from 1988 and 1990 revealed that cultural heterogeneity matters for adolescents' realization of their educational goals as well (Merolla 2016).

While these results strengthen our confidence in the theoretical model, it is an open question whether they can also be applied to the German school context.

\section{Present study and the German context}

As stated in the Introduction, the German school system is highly stratified and characterized by early between-school tracking. After four years ${ }^{2}$ of primary school, students are assigned to a secondary school track (by the age of 10). The least academically demanding track is Hauptschule, which ends after $9^{\text {th }}$ grade and has a very practical orientation. More academically demanding, but still with a focus on preparing students for vocational training, Realschule ends after $10^{\text {th }}$ grade. The Gymnasium is the track most academically demanding and qualifies students after the $12^{\text {th }}$ respectively $13^{\text {th }}$ grade (depending on the federal state) with an entrance certificate for university, the Abitur. Besides those three tracks, Gesamtschulen have been established that provide its students with the opportunity to earn each secondary school exam within the same school.

While the standard route to attain Abitur is attending Gymnasium, students being placed

\footnotetext{
${ }^{2}$ In some federal states, primary education lasts six years.
} 
Figure 1 Schematic representation of the pathways to Abitur

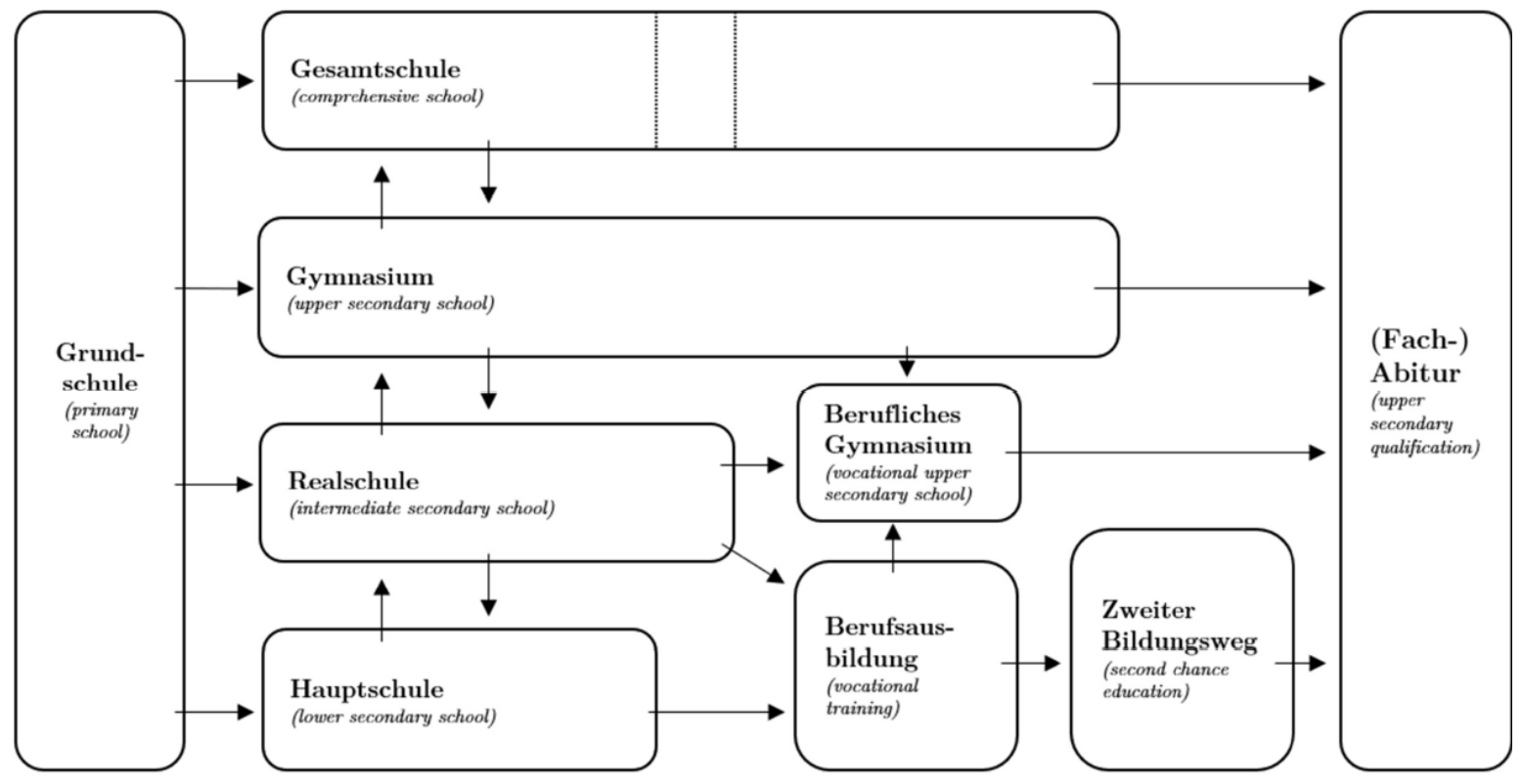

Source: Based on Schindler (2017)

in lower school tracks can revise their initial placement by switching between tracks later on (refer to Figure 1 for a schematic representation of the pathways to Abitur in Germany). Moreover, the strong vocational education system in Germany offers the possibility to earn Abitur at one of the berufliche Gymnasien. At those schools, students with an intermediate secondary degree can earn Fachabitur, qualifying them for entrance to universities of applied science. With a lower secondary degree, it is possible to earn an intermediate secondary degree along with the vocational training and then continue to Abitur via second chance education.

Due to the study's interest in explaining the realization of Abitur aspirations for students not taking the standard path, i.e. attending Gymnasium, the focus is on students at Haupt-, Real- and Gesamtschulen. ${ }^{3}$ For the same reason, the focus is on students holding aspirations for a university entrance certificate. This includes both general higher education entrance qualifications and those that qualify for entering universities of applied sciences.

To examine the influence of cultural heterogeneity on the realization of Abitur aspirations, this study examines whether aspirations students hold when they are in $9^{\text {th }}$ grade (when respondents are typically 15 years old), are realized five years later (when the majority of respondents is 20 years old) after the standard period to achieve an Abitur is over. Because in Germany compulsory general education ends after 9 years ${ }^{4}, 9^{\text {th }}$ grade serves as a good point of reference. Students are approaching the time where they need to make a decision about their future school career and if necessary change schools. So in this decision process, adolescents should have a reasonably clear sense of what education they aspire.

\footnotetext{
${ }^{3}$ Moreover, due to its purpose to qualify students for university, Gymnasien are culturally homogeneous environments, where virtually all students aim for Abitur, which leads to no variation on the independent variable heterogeneity in the respective classrooms.

${ }^{4}$ In some federal states, compulsory education ends after 10 years.
} 


\section{Data and measurement}

This study uses the German 'Children of Immigrants Longitudinal Survey in Four European Countries' (CILS4EU) (Kalter et al. 2021, 2017, 2015, 2014) which started in 2010 with a sample of $9^{\text {th }}$ graders in Germany. ${ }^{5}$ Within a sample of all schools enrolling the target population (participation: 144 schools, resp. 99 percent), two classes were selected randomly (participation: 271 classes, resp. 99 percent) and all students in theses classes were asked to participate (participation: 5,013 students, resp. 81 percent). This sampling approach allows for the systematic investigation of differences between school classes with different levels of aspiration heterogeneity. Moreover, this makes it possible to rely on peers' own statements about their educational values and aspiration rather than students' perceptions of their peers' values and aspirations. This is a more reliable measure because students' reports about their peers are prone to projection bias, leading to an overestimation of the similarity of oneself with one's peers (Bauman and Fisher 1986).

Because wave 1 was collected when adolescents were in $9^{\text {th }}$ grade and data collection took place before the end of each subsequent school year, adolescents' first report of attaining Abitur was by the time there were interviewed in wave 5 . To account for federal states in which time to Abitur is 13 years, I use information from wave 6 as well to assess whether adolescents aspiring to attain a Abitur actually did so. If not stated otherwise, all independent measures are taken from wave 1. Due to panel attrition, sample size in wave 6 dropped to $2,307 .{ }^{6}$ Linear probability models with clustered standard errors are employed to take into account the nested data structure. Weights are applied that correct for sampling probability in wave 1 (the initial design weight) as well as drop out due to panel attrition in wave 6 (a panel weight that adjusts for participation probability in wave 6) (CILS4EU-DE 2021).

As stated above, the analyses are restricted to students attending Haupt-, Real- and Gesamtschulen holding Abitur aspirations in $9^{\text {th }}$ grade.

\subsection{Key variables}

Abitur aspirations were operationalized using adolescents' responses regarding the highest level of education they wish to get when they attended $9^{\text {th }}$ grade. Students who wished to get a degree from upper secondary school or a university degree were coded as aspiring Abitur. Students indicating that they wish to get no degree, a degree from lower or from intermediate secondary school were coded as not having aspirations for a university entrance certificate and were not considered in the analyses.

Realization of Abitur aspirations: In wave 6, a life history calendar has been administered in which adolescents were asked to give a detailed record of their school career since wave 1 (including all different schools they visited and the degrees they have earned). If the highest degree they earned was Abitur or Fachabitur, they were coded as having realized their aspirations. If they did not attain a degree, or the highest degree they attained was a lower (Hauptschulabschluss) or intermediate secondary degree (Realschulabschluss) or an 'other' degree, they were coded as not having realized their Abitur aspiration.

\footnotetext{
${ }^{5}$ Due to its focus on the integration of migrants, schools with high shares of immigrant students have been oversampled.

${ }^{6} \mathrm{~A}$ refreshment sample was drawn in wave 6 . However, this is not suitable for my analyses because information on the key independent measure is missing.
} 
Students who did not participate in the life history calendar were administered a short version of the questionnaire in which they were asked whether they earned a degree since the last time they were interviewed- and if they did so which type of degree this was. For adolescents that participated in waves 5 and 6 , the highest degree reported was used to determine whether they attained a Abitur. In cases of non participation in wave 5, only information of wave 6 was used.

Cultural heterogeneity: The measure of cultural heterogeneity in class is based on the aspiration variable, distinguishing between students aspiring a lower secondary ${ }^{7}$, an intermediate secondary, an upper secondary and a tertiary degree. Due to the ordinal nature of this variable, using the variance is inappropriate. Therefore, I follow Harding's (2011) strategy, and use a measure that captures the ordinal variation (Blair and Lacy 2000) in classmates' self-reported educational aspirations. It reflects the difference between the distribution of aspirations that is observed and one where all aspirations are evenly divided between all levels of aspiration:

$$
l^{2}=\frac{\sum_{i=1}^{k-1}\left(F_{i}-.5\right)^{2}}{(k-1) / 4}
$$

where $k$ represents the number of response categories (in my case $k=4$ ) and $F_{i}$ represents the cumulative share for category $i$. It is normalized to a range from 0 to 1 and adjusted for bias in small samples with small values of $l^{2}$ using the following formula: $l_{a d j}^{2}=\frac{\left(1-l^{2}\right)}{(N-1)}$. Because $l^{2}$ is a measure of concentration, $1-l^{2}$ is taken as the measure of educational heterogeneity.

14 classes were excluded due to a participation rate of less than $50 \%$ on the class level.

\subsection{Control variables}

Because selection into schools is associated with socio-economic status (Juvonen 2019) and socio-economic status is associated with realization of educational aspirations (Rosenbaum 2011; Hanson 1994), parental education and migration background are controlled.

Parental education: Besides the questionnaires administered to adolescents in school, telephone interviews were conducted with one parent in wave 1 . While parents' reports of their own and their partner's education is available from this source, total parental participation rate was $78 \%$. So in cases, in which no information was provided by the parents, information provided by the adolescents was used. Information on parental education was available in the youth questionnaire in wave 1 and wave 3 . If parents' reports were missing, the information provided by the child in wave 3 was used, assuming that children's knowledge of their parental education increases with age. Only if this information is not available as well, I rely on children's reports from wave 1.

Migration status: Students who immigrated themselves or who have at least one foreign-born parent, therefore having less experience with the German school system, are coded as having a migration background. All other adolescents are treated as having no migration background. While this information is initially taken from wave 1, in cases in which student have missing information in wave 1 but non-missing information in a later wave, this information is used.

\footnotetext{
${ }^{7}$ This includes one respondent who responded 'no degree'.
} 
Table 1 Descriptive statistics for sample of analyses $(\mathrm{N}=1,079)$

\begin{tabular}{|c|c|c|c|c|c|}
\hline & & Mean & $\mathrm{SD}$ & Min & Max \\
\hline \multicolumn{2}{|c|}{ Abitur attained } & 0.48 & & 0 & 1 \\
\hline \multicolumn{2}{|c|}{ Cultural heterogeneity in class } & 0.49 & 0.11 & 0.1 & 1.0 \\
\hline \multicolumn{2}{|c|}{ Average aspiration in class $>=$ Abitur (Ref: $<$ Abitur $)$} & 0.94 & 0.23 & 0 & 1 \\
\hline \multicolumn{2}{|c|}{ Average cognitive ability in class } & 19.09 & 1.65 & 13.1 & 22.6 \\
\hline \multicolumn{2}{|c|}{$\%$ Abitur aspirations in class } & 62.82 & 16.99 & 8.3 & 96.2 \\
\hline \multicolumn{2}{|c|}{ Individual cognitive ability } & 19.58 & 3.50 & 6.0 & 27.0 \\
\hline \multirow[t]{3}{*}{ German grade } & very good/good & 0.33 & & & \\
\hline & satisfactory & 0.47 & & & \\
\hline & sufficient/poor & 0.20 & & & \\
\hline \multicolumn{2}{|c|}{ Female (Ref: male) } & 0.43 & & 0 & 1 \\
\hline \multicolumn{2}{|l|}{ Age } & 14.68 & 0.70 & 13.0 & 17.0 \\
\hline \multicolumn{2}{|c|}{ Academic parent(s) } & 0.82 & & 0 & 1 \\
\hline \multicolumn{2}{|c|}{ Migration background } & 0.53 & & 0 & 1 \\
\hline \multicolumn{2}{|c|}{$\%$ Academic parent(s) in class } & 11.72 & 10.42 & 0.0 & 75.0 \\
\hline \multicolumn{2}{|c|}{$\%$ Migration background in class } & 38.13 & 22.45 & 0.0 & 95.7 \\
\hline \multirow[t]{3}{*}{ School track: } & Hauptschule & 0.20 & & & \\
\hline & Realschule & 0.47 & & & \\
\hline & Gesamtschule & 0.33 & & & \\
\hline
\end{tabular}

Source: CILS4EU (unweighted)

The same holds true for students who give inconsistent information across waves. In those cases, information from the most recent wave is used, assuming that knowledge increases with higher age.

Depending on the school track individuals attend, they have different opportunities to realize the same educational aspiration. Moreover, there is evidence for a school track-effect on the development of educational goals (Karlson 2015; Bittmann and Schindler 2021). To capture those differences, I control for school track, distinguishing between Haupt-, Real- and Gesamtschulen.

Moreover, cognitive ability, is included to control for the fact that the influence on students' aspiration realization is limited by their cognitive abilities. This measure is a sum index of the correct answers of all the items from the cognitive ability test and is provided by CILS4EU. For the same reason, the school grade in German in wave 1 is controlled. Because peer influences work differently for boys and girls (Kiuru, Aunola, Vuori, and Nurmi 2007), gender is held constant as well. If information in wave 1 was not available, information is taken from a latter wave. To measure respondent's age, information was also used from other waves. Although date of birth is a constant characteristic, information was not always identical across waves. Therefore I took the birth month and year that was mentioned the most often (assuming that this information is the most reliable one). Only if this was not possible, I took the information of the most recent wave. 
Table 2 Realization of Abitur aspirations, by school track attended in $9^{\text {th }}$ grade grade

\begin{tabular}{lcccccccc}
\hline & \multicolumn{2}{c}{ Hauptschule } & \multicolumn{2}{c}{ Realschule } & \multicolumn{2}{c}{ Gesamtschule } & \multicolumn{2}{c}{ Total } \\
\cline { 2 - 9 } & $\mathrm{N}$ & $\%$ & $\mathrm{~N}$ & $\%$ & $\mathrm{~N}$ & $\%$ & $\mathrm{~N}$ & $\%$ \\
\hline Abitur & 28 & 18.4 & 361 & 63.3 & 163 & 45.5 & 552 & 51.1 \\
No Abitur & 122 & 81.6 & 209 & 36.7 & 196 & 54.5 & 527 & 48.9 \\
\hline Total & 150 & 100 & 570 & 100 & 359 & 100 & 1,079 & 100 \\
\hline
\end{tabular}

Source: CILS4EU (unweighted)

To rule out that variables correlated with heterogeneity drive the results, various controls on the class-level are added as well: average educational aspirations, share of students holding Abitur aspirations, average ability, share of academic parents and share of students with migration background within each classroom.

\section{Results}

Before establishing whether heterogeneity influences realization of Abitur aspirations, I investigate the share of students realizing their aspirations at all (Table 2). In total, about half the students with Abitur aspirations actually finish school with an Abitur degree. Because students are sorted into the different school tracks based on their ability, it can be expected that the share of realized Abitur aspirations differs between tracks with different levels of academic demand. The expected picture is found. At Realschulen, the academically most demanding track, almost two thirds realized their Abitur aspirations. This share is substantially lower at Hauptschulen, with a fifth realizing their aspirations. The share of students realizing their aspiration at Gesamtschulen is in between, with half the students realizing their aspirations.

What role does heterogeneity in aspirations play on Abitur realization? A comparison of the heterogeneity distribution for students who realized their aspirations and those who did not (Figure 2) suggests that the role is not substantial. While students with an Abitur seem to come from slightly more homogeneous classrooms, differences are not very pronounced.

This impression holds when looking at the results of the linear probability model visualized in Figure 3 (numeric regression results in Table 4 in the Appendix). While the coefficient of heterogeneity is negative, suggesting a lower likelihood of realizing one's Abitur aspirations with higher heterogeneity in class, the coefficient is rather small $(-0.220$ in the bivariate and -0.049 in the multivariate model). Moreover, confidence intervals are large and include zero, therefore the coefficients do not reach significance. This indicates that heterogeneity does not play a substantial role in the realization of students' Abitur aspirations.

This result holds under different specifications of the model (see Table 4 in the Appendix). The former model treated students still in education as not having attained Abitur. This could bias the results because they might succeed in achieving their aspirations after wave 6 . While this would still be consistent with the theoretical framework to the extent that people are less straightforward in realizing their goals when cultural heterogeneity is high, it could disguise an effect of heterogeneity. To check for this possibility, two different model specifications are estimated: one excluding adolescents still in school and one that extends the time frame of 
Figure 2 Distribution of cultural heterogeneity, by Abitur attainment
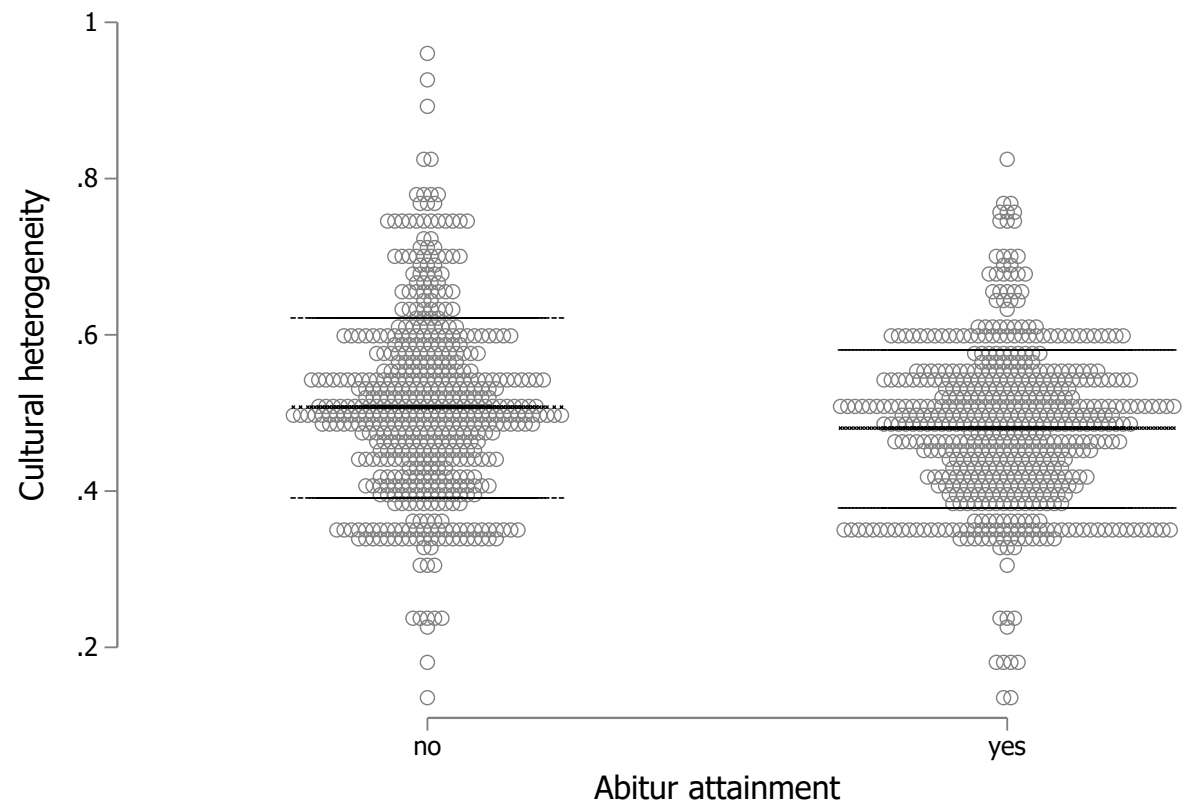

Notes: Dotted lines at mean; solid lines at one SD above resp below mean Source: CILS4EU (unweighted)

Abitur attainment to wave 7 . Neither model yielded substantially different results.

To get a greater contrast between different levels of cultural heterogeneity, a categorical version of the variable is constructed that distinguishes between classrooms with high, medium and low heterogeneity. ${ }^{8}$ Again, results are similar to the original model and do not support the hypothesis of a negative effect of cultural heterogeneity on the realization of Abitur aspirations.

\subsection{Are there differential effects for certain groups?}

Even though the analyses above do not support the hypothesis that cultural heterogeneity hampers the realization of Abitur aspirations, my analytical approach could hide effects for certain groups who are especially susceptible to peer influence because they receive less reliable information from their parents. One such group are students with migration background. Research shows that the aspiration-achievement gap is more pronounced for this group of students: they hold higher aspirations than students with no migration background but at the same time, they are less likely to translate their high aspirations into respective degrees (Morgan 2004; Kao and Tienda 1998; Salikutluk 2016). Subgroup analyses for students with

\footnotetext{
${ }^{8}$ I experimented with different versions of heterogeneity categories. For the version presented in the appendix, the entire sample was split into thirds. Alternative versions were created by building categories within each school track. A version that grouped classes with one standard deviation and more above the mean versus classes with one standard deviation and less below the mean versus all classes in between was constructed as well. All specifications yielded results that are not substantially different from the one presented in the appendix.
} 
Figure 3 Coefficent plot of linear probability models on Abitur attainment

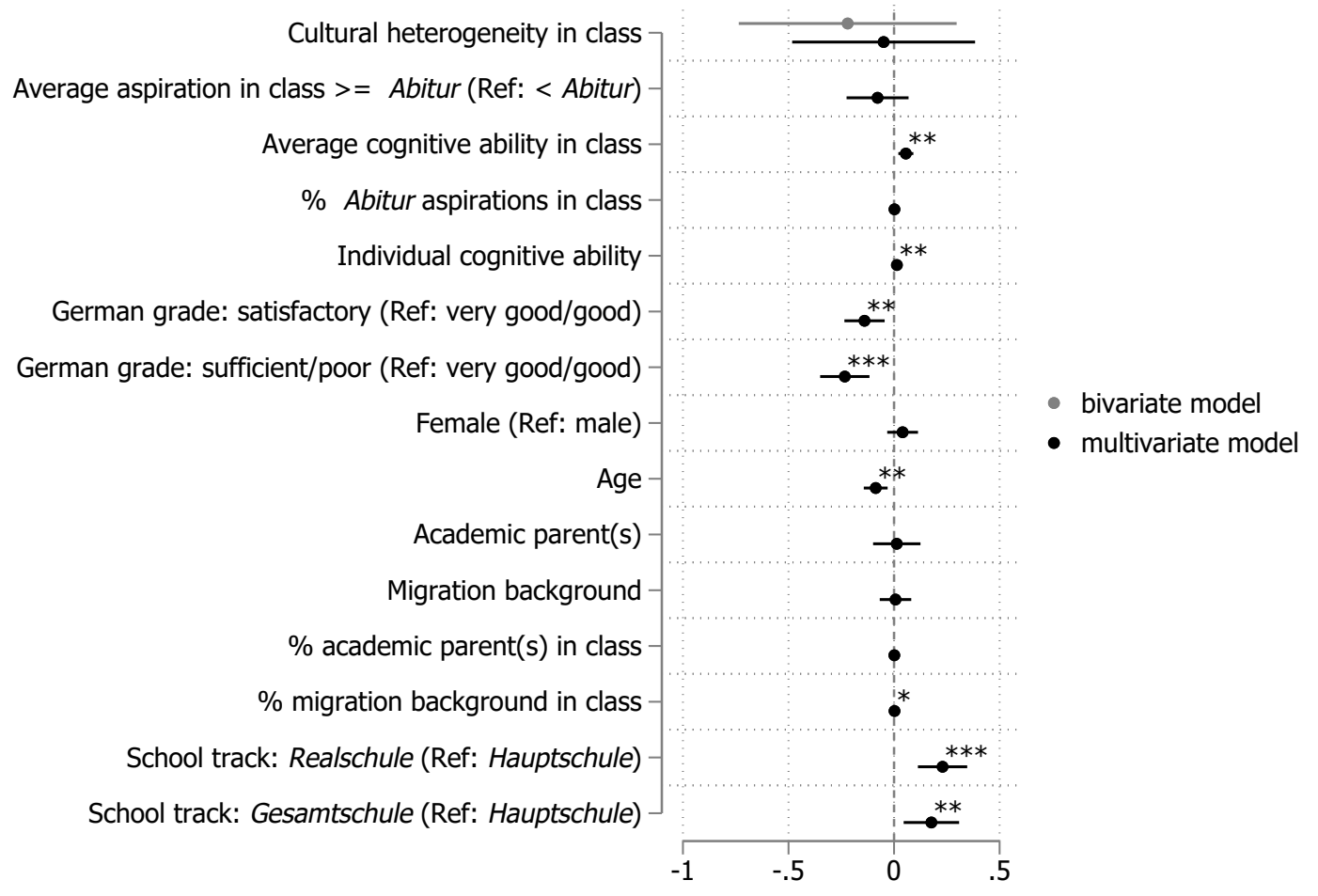

Notes: ${ }^{*} \mathrm{p}<.05,{ }^{* *} \mathrm{p}<.01,{ }^{* * *} \mathrm{p}<.001$; lines represent $95 \%$ confidence intervals Source: CILS4EU (weighted)

and without migration background (Figure 4; regression table in Table 4 in the Appendix) show that the (non-) effect of cultural heterogeneity is the same for both groups. Neither for students with nor for students without migration background, heterogeneity seems to decrease their likelihood of realizing their Abitur aspirations.

Another group that could be especially susceptible to the influence of aspiration heterogeneity are students whose parents are not academics. For those students, attaining Abitur is not necessary to maintain the status of their parents (Breen and Goldthorpe 1997), so they might not have such a pronounced preferences for Abitur to begin with. This could mean that this group is especially susceptible for distractions from their original educational pathway. While results hint to contrary effects for students with and without academic parents in such a way that heterogeneity is more detrimental for students without an academic background, differences are not very pronounced.

Another possibility are differential effects by school track due to different extents of barriers for attaining Abitur. Gesamtschulen have less barriers compared to Haupt- and Realschulen because changing to a different track can be achieved within the same school. On the other hand, barriers at Hauptschulen should be highest given their distance to Gymnasium. While there are differences between school tracks, the results do not favor a negative heterogeneity effect. Instead, effect sizes at Haupt- and Gesamtschulen are again very small and not significant, suggesting that cultural heterogeneity does not play a role in the realization of Abitur aspirations. The coefficient for Realschulen, although not reaching significance, even favors an interpretation of a positive heterogeneity effect. 
Figure 4 Predicted probability of Abitur attainment: Subgroup analyses
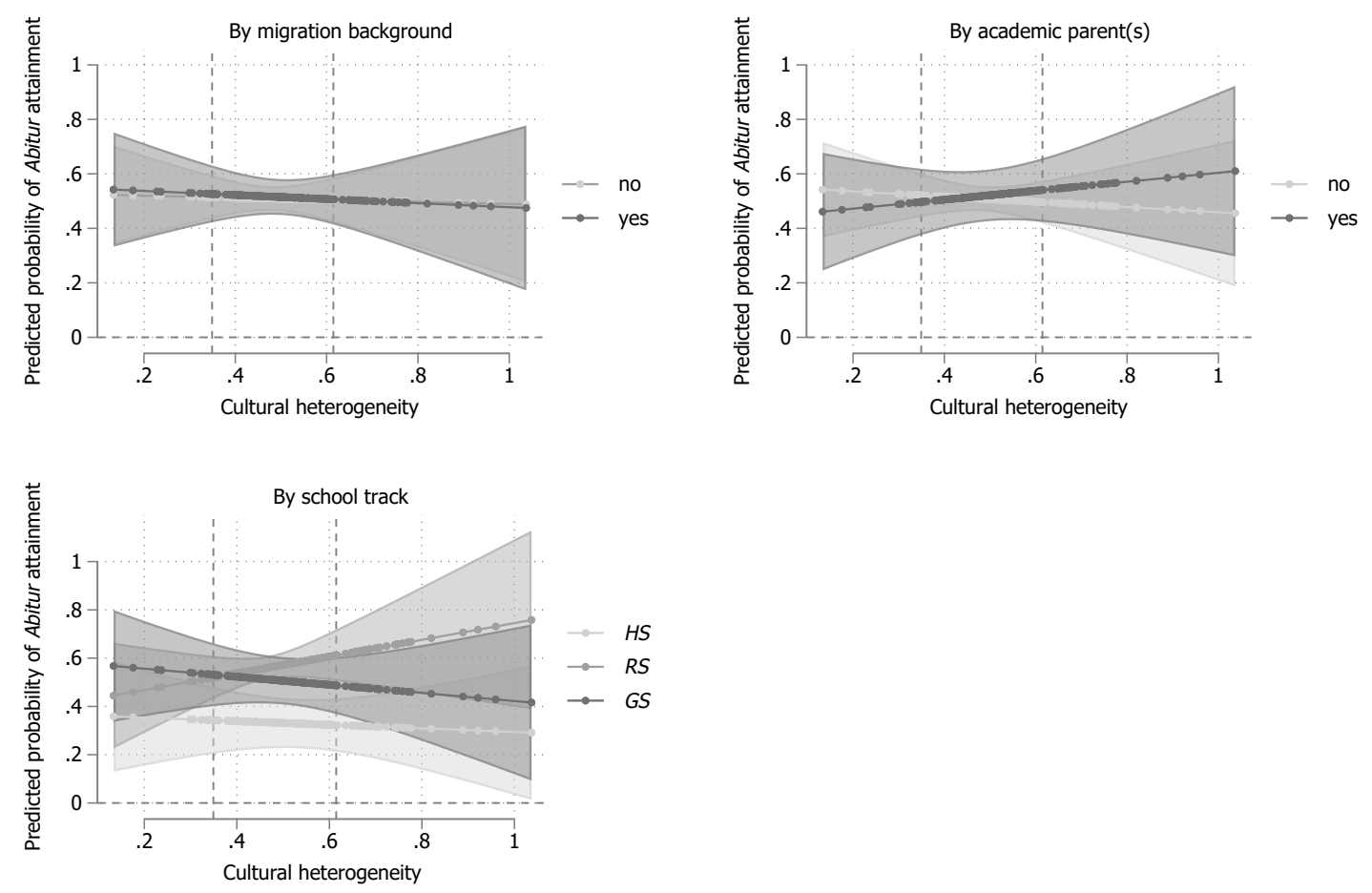

Notes: between vertical dashed lines: $80 \%$ of the sample; each dot represents a classroom; additional variables: average aspiration in class, average cognitive ability in class, $\%$ Abitur aspirations in class, individual cognitive ability, German grade, gender, age, academic parent(s), migration background, \% academic parent(s) in class , \% migration background in class, school track

Source: CILS4EU (weighted)

\section{Conclusion}

Building on the research on cultural heterogeneous neighborhoods, this article tested a new explanation of what enables students in Germany's stratified secondary school system to realize their Abitur aspirations when they follow non-standard paths to Abitur (i.e. those attending Haupt-, Real- und Gesamtschulen). Applying a longitudinal perspective, I tested whether cultural heterogeneity in $9^{\text {th }}$ grade (when the majority of adolescents is 15 years old) is related to attainment of Abitur after the standard period of schooling. My analyses found no evidence for a substantial effect of heterogeneous aspiration in class on Abitur attainment, neither for the total sample nor when considering different subgroups. This suggests that findings on the importance of cultural heterogeneity in U.S. neighborhoods are not readily applicable to the German school context.

Different explanations can account for this. While I argued in the Introduction that high stratification and diverse pathways to Abitur should make adolescents especially vulnerable to the influence of cultural heterogeneity, the opposite could be true as well. High stratification leads to relatively homogeneous peer environments (Buchmann and Dalton 2002), so variance on the heterogeneity variable could be not pronounced enough. This would be consistent with research that find peer effects in comprehensive school systems but not in highly tracked ones 
(Lorenz, Boda, Salikutluk, and Jansen 2020; Dollmann and Rudolphi 2020).

Another possibility is that those students, who were the most affected by heterogeneity were those who dropped out of the study due to an unobserved trait influencing both. While the comparison of the drop out sample (see Table 5 in the Appendix) to the sample of analyses (see Table 1) does not reveal substantial differences between both groups and I took precautions by applying respective weights, it would be worthwhile to test the research question with different data that has less panel attrition.

Taking a step back from the methodological issues, there is also a theoretical issue worth exploring. What is missing in the current discussion on cultural heterogeneity and educational success is the possibility of heterogeneity having a positive influence as well - depending on one's own level of educational aspirations. Harding developed his theory in the context of aspirations to go to college. When looking at the highest educational degree one can earn, more heterogeneity equals more aspirations below ones' own, so the assumption of a negative effect of heterogeneity is reasonable. however, in the case of aspirations for lower degrees, the case could be different. In this case, more heterogeneity could implicate exposure to higher aspirations than one's own. So being distracted from the original educational path could mean achieving more than aspired. A student aspiring to earn an intermediate secondary degree might even gain more from being in a cultural heterogeneous environment with peers who want to earn higher degrees, while educational models for attaining an upper secondary degree might not be in his toolkit in a homogeneous environment in which all his peers aim for an intermediate secondary degree as well. This relates to earlier findings, that especially adolescents with high levels of self-efficacy are negatively affected by cultural heterogeneity (Merolla 2016) and that weak students profit most from heterogeneous learning environments.

Against this backdrop, the present study is a first important step in testing whether (Harding 2007) idea of cultural heterogeneity can be generalized to different countries and contexts and provides a contribution to our knowledge of students educational success on non-standard paths to Abitur.

\section{Acknowledgments}

CILS4EU was funded within the NORFACE ERA NET Plus Migration in Europe-programme. CILS4EU-DE is funded within the long-term programme of the German Research Foundation (DFG). Special thanks are due to the young adults participating in the studies.

This paper benefited from valuable feedback from Clemens Kroneberg, Sandra Krapf, and Jörg Dollmann . 


\section{References}

Bauman, K. E. and L. A. Fisher (1986). On the measurement of friend behavior in research on friend influence and selection: Findings from longitudinal studies of adolescent smoking and drinking. Journal of Youth and Adolescence 15(4), 345-353.

Berg, M. T., E. A. Stewart, E. Stewart, and R. L. Simons (2013). A multilevel examination of neighborhood social processes and college enrollment. Social Problems 60(4), 513-534.

Biewen, M. and M. Tapalaga (2017). Life-cycle educational choices in a system with early tracking and 'second chance' options. Economics of Education Review 56, 80-94.

Bittmann, F. and S. Schindler (2021). Analysing diversion processes in german secondary education: School-track effects on educational aspirations. Kölner Zeitschrift für Soziologie und Sozialpsychologie 73(2), 231-257.

Blair, J. and M. G. Lacy (2000). Statistics of ordinal variation. Sociological Methods $\&$ Research 28(3), 251-280.

Breen, R. and J. H. Goldthorpe (1997). Explaining educational differentials. Rationality and Society 9(3), 275-305.

Buchholz, S. and A. Schier (2015). New game, wew chance? social inequalities and upgrading secondary school qualifications in west germany. European Sociological Review 31(5), 603615 .

Buchmann, C. and B. Dalton (2002). Interpersonal influences and educational aspirations in 12 countries: The importance of institutional context. Sociology of Education 75(2), 99.

Buchmann, C. and H. Park (2009). Stratification and the formation of expectations in highly differentiated educational systems. Research in Social Stratification and Mobility 27(4), $245-267$.

Buchmann, M. (1989). The script of life in modern society: Entry into adulthood in a changing world. University of Chicago Press.

Burke, M. A. and T. R. Sass (2013). Classroom peer effects and student achievement. Journal of Labor Economics 31(1), 51-82.

CILS4EU-DE (2021). children of immigrants longitudinal survey in four european countries - germany. codebook. wave 6 - 2016/17, v.0.0. Technical report, Mannheim University.

Dollmann, J. and F. Rudolphi (2020). Classroom composition and language skills: the role of school class and friend characteristics. British Journal of Sociology of Education 41(8), $1200-1217$.

Domina, T., A. Conley, and G. Farkas (2011). The link between educational expectations and effort in the college-for-all era. Sociology of Education 84(2), 93-112.

Fletcher, J. M. (2012). Similarity in peer college preferences: New evidence from texas. Social Science Research 41(2), 321-330.

Hallinan, M. T. and R. A. Williams (1990). Students' characteristics and the peer-influence process. Sociology of Education 63(2), 122-132.

Hanson, S. L. (1994). Lost Talent. Unrealized educational aspirations and expectations among U.S. youths. Sociology of Education 67(3), 159-183. 
Hanushek, E. A., J. F. Kain, J. M. Markman, and S. G. Rivkin (2003). Does peer ability affect student achievement? Journal of Applied Econometrics 18(5), 527-544.

Harding, D. J. (2007). Cultural context, sexual behavior, and romantic relationships in disadvantaged neighborhoods. American Sociological Review 72(3), 341-364.

Harding, D. J. (2010). Living the drama: Community, conflict, and culture among inner-city boys. University of Chicago Press.

Harding, D. J. (2011). Rethinking the cultural context of schooling decisions in disadvantaged neighborhoods: From deviant subculture to cultural heterogeneity. Sociology of Education $84(4), 322-339$.

Jacob, B. and T. Wilder (2010). Educational expectations and attainment. NBER Working Paper Series , No. 15683.

Juvonen, J. (2019). The potential of schools to facilitate and constrain peer relationships. In W. M. Bukowski, B. Laursen, and K. H. Rubin (Eds.), Handbook of Peer Interactions, Relationships, and Groups, pp. 491-509. The Guilford Press.

Kalter, F., A. F. Heath, M. Hewstone, J. O. Jonsson, M. Kalmijn, I. Kogan, and F. V. Tubergen (2015). Children of Immigrants Longitudinal Survey in Four European Countries (CILS4EU) - Reduzierte Version. Reduzierter Datenbestand zum Download und zur off-site Nutzung.

Kalter, F., A. F. Heath, M. Hewstone, J. O. Jonsson, M. Kalmijn, I. Kogan, and F. V. Tubergen (2017). Children of Immigrants Longitudinal Survey in Four European Countries (CILS4EU) - Reduzierte Version. Reduzierter Datenbestand zum Download und zur off-site Nutzung.

Kalter, F., A. F. Heath, M. Hewstone, J. O. Jonsson, M. Kalmijn, I. Kogan, F. V. Tubergen, C. Kroneberg, L. A. Rydell, S. B. Låftman, J. Dollmann, P. Engzell, S. Geven, A. Horr, L. Huuva, K. Jacob, E. Jaspers, H. Kruse, P. Meenakshi, F. Rudolphi, Z. Salikutluk, S. Smith, and P. V. Zantvliet (2014). Children of Immigrants Longitudinal Survey in Four European Countries (CILS4EU) - Reduzierte Version. Reduzierter Datenbestand zum Download und zur off-site Nutzung.

Kalter, F., I. Kogan, and J. Dollmann (2021). Children of Immigrants Longitudinal Survey in Four European Countries - Germany (CILS4EU-DE) - Reduzierte Version. Reduzierter Datenbestand zum Download und zur off-site Nutzung.

Kao, G. and M. Tienda (1998). Educational aspirations of minority youth. American Journal of Education 106(3), 349-384.

Karlson, K. B. (2015). Expectations on track? high school tracking and adolescent educational expectations. Social Forces 94(1), 115-141.

Kirk, D. S. (2009). Unraveling the contextual effects on student suspension and juvenile arrest: The independent and interdependent influences of school, neighborhood and family social controls. Criminology $47(2), 479-520$.

Kiss, D. (2013). The impact of peer achievement and peer heterogeneity on own achievement growth: Evidence from school transitions. Economics of Education Review 37, 58-65.

Kiuru, N., K. Aunola, J. Vuori, and J.-E. Nurmi (2007). The role of peer groups in adolescents' educational expectations and adjustment. Journal of Youth and Adolescence 36(8), 9951009 . 
Lehmann, R. H. (2006). Zur Bedeutung der kognitiven Heterogenität von Schulklassenfür den Lernstand am Ende der Klassenstufe 4. In A. Schründer-Lenzen (Ed.), Risikofaktoren kindlicher Entwicklung. Migration, Leistungsangst und Schulübergang, pp. 109-121. VS Verlag für Sozialwissenschaften.

Lorenz, G., Z. Boda, Z. Salikutluk, and M. Jansen (2020). Social influence or selection? peer effects on the development of adolescents' educational expectations in germany. British Journal of Sociology of Education 41(5), 643-669.

Marotta, L. (2017). Peer effects in early schooling: Evidence from Brazilian primary schools. International Journal of Educational Research 82, 110-123.

Merolla, D. M. (2016). Self-efficacy and academic achievement. Sociological Perspectives $60(2), 378-393$.

Morgan, S. L. (2004). Methodologist as arbitrator: Five models for Black-White differences in the causal effect of expectations on attainment. Sociological Methods 8 Research 33(1), $3-53$.

Reynolds, J. R. and M. K. Johnson (2011). Change in the stratification of educational expectations and their realization. Social Forces 90(1), 85-110.

Riegle-Crumb, C., G. Farkas, and C. Muller (2006). The role of gender and friendship in advanced course taking. Sociology of Education 79(3), 206-228.

Rodkin, P. C. and A. M. Ryan (2012). Child and adolescent peer relations in educational context. In K. R. Harris, S. Graham, and T. C. Urdan (Eds.), APA Educational psychology handbook, APA handbooks in psychology, pp. 363-389. American Psychological Association.

Rosenbaum, J. E. (2011). The complexities of college for all: Beyond fairy-tale dreams. Sociology of Education 84(2), 113-117.

Salikutluk, Z. (2016). Why do immigrant students aim high? Explaining the aspirationachievement paradox of immigrants in Germany. European Sociological Review 32(5), $581-592$.

Scharenberg, K. (2012). Do secondary students learn more in homogeneous or heterogeneous classes? the importance of classroom composition for the development of reading achievement in secondary school. Online Educational Research Journal 3(12), 1-11.

Schindler, S. (2017). School tracking, educational mobility and inequality in german secondary education: developments across cohorts. European Societies 19, 28-48.

Schneider, B. and D. Stevenson (1999). The ambitious generation: America's teenagers, motivated but directionless. Yale University Press.

Schoon, I. (2010). Planning for the future: Changing education expectations in three british cohorts. Historical Social Research 35(2), 99-119. 


\section{Appendix}

Table 3 Results of linear probability models on Abitur attainment

\begin{tabular}{|c|c|c|}
\hline & Model (1) & Model (2) \\
\hline Cultural heterogeneity in class & $\begin{array}{l}-0.220 \\
(-0.839)\end{array}$ & $\begin{array}{l}-0.049 \\
(-0.225)\end{array}$ \\
\hline $\begin{array}{l}\text { Average aspiration in class }>=\text { Abitur } \\
\text { (Ref: }<\text { Abitur) }\end{array}$ & & $\begin{array}{l}-0.078 \\
(-1.050)\end{array}$ \\
\hline Average cognitive ability in class & & $\begin{array}{l}0.056^{* *} \\
(3.093)\end{array}$ \\
\hline$\%$ Abitur aspirations in class & & $\begin{array}{c}0.002 \\
(0.970)\end{array}$ \\
\hline Individual cognitive ability & & $\begin{array}{l}0.013^{* *} \\
(2.619)\end{array}$ \\
\hline $\begin{array}{l}\text { German grade: satisfactory } \\
\text { (Ref: very good/good) }\end{array}$ & & $\begin{array}{l}-0.140^{* *} \\
(-2.897)\end{array}$ \\
\hline $\begin{array}{l}\text { German grade: sufficient/poor } \\
\text { (Ref: very good/good) }\end{array}$ & & $\begin{array}{l}-0.233^{* * *} \\
(-3.941)\end{array}$ \\
\hline Female & & $\begin{array}{c}0.041 \\
(1.097)\end{array}$ \\
\hline Age & & $\begin{array}{l}-0.087^{* *} \\
(-3.036)\end{array}$ \\
\hline Academic parent(s) & & $\begin{array}{c}0.013 \\
(0.226)\end{array}$ \\
\hline Migration background & & $\begin{array}{c}0.007 \\
(0.182)\end{array}$ \\
\hline$\%$ Academic parent(s) in class & & $\begin{array}{c}0.001 \\
(0.407)\end{array}$ \\
\hline$\%$ Migration background in class & & $\begin{array}{r}0.002^{*} \\
(1.986)\end{array}$ \\
\hline $\begin{array}{l}\text { School track: Realschule } \\
\text { (Ref: Hauptschule) }\end{array}$ & & $\begin{array}{l}0.230^{* * *} \\
(3.882)\end{array}$ \\
\hline $\begin{array}{l}\text { School track: Gesamtschule } \\
\text { (Ref: Hauptschule) }\end{array}$ & & $\begin{array}{l}0.177^{* *} \\
(2.655)\end{array}$ \\
\hline Constant & $\begin{array}{l}0.616^{* * *} \\
(4.706)\end{array}$ & $\begin{array}{c}0.186 \\
(0.330)\end{array}$ \\
\hline $\begin{array}{l}R^{2} \\
\text { Observations }\end{array}$ & $\begin{array}{l}0.002 \\
1,079\end{array}$ & $\begin{array}{l}0.192 \\
1,079\end{array}$ \\
\hline
\end{tabular}

Notes: ${ }^{*} \mathrm{p}<.05,{ }^{* *} \mathrm{p}<.01,{ }^{* * *} \mathrm{p}<.001$

Source: CILS4EU (weighted) 


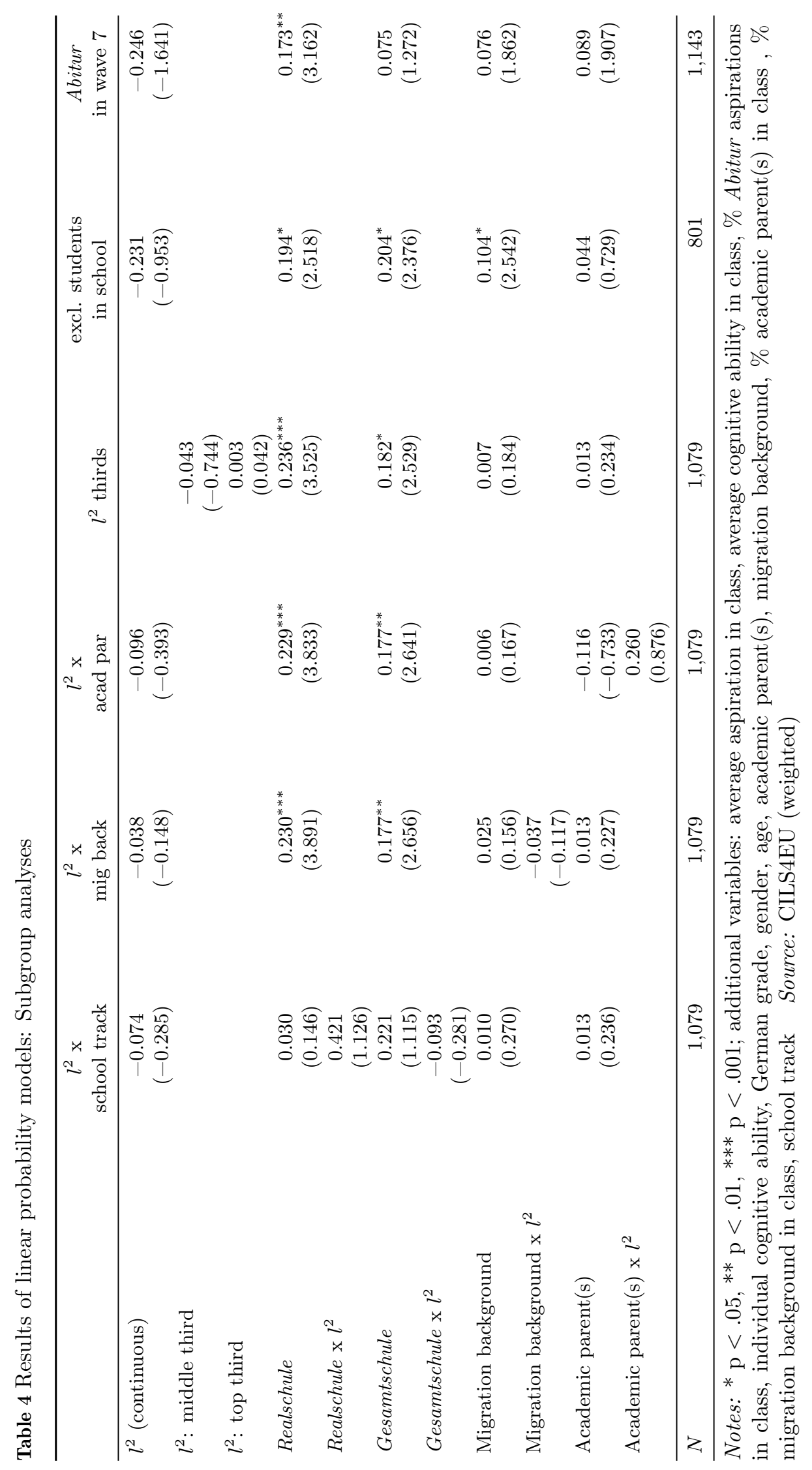


Table 5 Descriptive statistics for respondents excluded from analyses $(\mathrm{N}=2,087)$

\begin{tabular}{|c|c|c|c|c|c|}
\hline & & Mean & $\mathrm{SD}$ & Min & $\operatorname{Max}$ \\
\hline \multicolumn{2}{|c|}{ Cultural heterogeneity } & 0.50 & 0.11 & 0.1 & 1.0 \\
\hline \multicolumn{2}{|c|}{ Average aspiration in class $>=$ Abitur $($ Ref: $<$ Abitur $)$} & 0.95 & & 0 & 1 \\
\hline \multicolumn{2}{|c|}{ Average cognitive ability in class } & 18.84 & 1.69 & 13.1 & 22.6 \\
\hline \multicolumn{2}{|c|}{$\%$ Abitur aspirations in class } & 60.82 & 17.50 & 7.1 & 96.2 \\
\hline \multicolumn{2}{|c|}{ Individual cognitive ability } & 19.17 & 3.68 & 1.0 & 27.0 \\
\hline \multirow[t]{3}{*}{ German grade: } & very good / good & 0.30 & & & \\
\hline & satisfactory & 0.47 & & & \\
\hline & sufficient / poor & 0.23 & & & \\
\hline \multicolumn{2}{|c|}{ Female (Ref: male) } & 0.49 & & 0 & 1 \\
\hline \multicolumn{2}{|l|}{ Age } & 14.75 & 0.73 & 13.0 & 17.0 \\
\hline \multicolumn{2}{|c|}{ Academic parent(s) } & 0.15 & & 0 & 1 \\
\hline \multicolumn{2}{|c|}{ Migration background } & 0.50 & & 0 & 1 \\
\hline \multicolumn{2}{|c|}{$\%$ Academic parent(s) in class } & 10.55 & 9.65 & 0.0 & 75.0 \\
\hline \multicolumn{2}{|c|}{$\%$ Migration background in class } & 40.26 & 22.10 & 0.0 & 95.7 \\
\hline \multirow[t]{3}{*}{ School track: } & Hauptschule & 0.27 & & & \\
\hline & Realschule & 0.42 & & & \\
\hline & Gesamtschule & 0.32 & & & \\
\hline
\end{tabular}

Source: CILS4EU (unweighted)

\section{Affiliation:}

Maria Gerth

Universität zu Köln (Germany)

E-mail: maria.gerth@posteo.de

\section{SocArXiv Website SocArXiv Preprints}

Preprint

URL/DOI GOES HERE https://socopen.org/ https://osf.io/preprints/socarxiv

Submitted: March 3, 2022 Accepted: March 3, 2022 